\title{
Microleakage of a Self-Adhesive Flowable Composite, a Self-Adhesive Fissure Sealant and a Conventional Fissure Sealant in Permanent Teeth with/without Saliva Contamination
}

\section{Zohre Sadat Hosseinipour ${ }^{1}$, Alireza Heidari2*, Mehdi Shahrabi², Kiana Poorzandpoush ${ }^{3}$}

1. Department of Pedodontics, Faculty of Dentistry, AJA University of Medical Sciences, Tehran, Iran

2. Department of Pediatric Dentistry, School of Dentistry, Tehran University of Medical Sciences, Tehran, Iran

3. Department of Pedodontics, Faculty of Dentistry, Shahid Beheshti University of Medical Sciences, Tehran, Iran

\begin{tabular}{ll}
\hline Article Info & A B S T R A C T \\
\hline Article type: & Objectives: Application of fissure sealants is a practical method for prevention of \\
Original Article & occlusal pit and fissure caries. Microleakage is an important factor affecting the \\
& success of fissure sealant treatment. This study aimed to assess the microleakage of \\
& a self-adhesive flowable composite, a self-adhesive fissure sealant and a conventional \\
& fissure sealant in permanent teeth with/without saliva contamination.
\end{tabular}

\section{Article history:}

Received: 27 May 2018

Accepted: 10 July 2018

Published: 30 August 2019

\section{* Corresponding author: \\ Department of Pediatric Dentistry, School of Dentistry, Tehran University of Medical Sciences, Tehran, Iran}

Email: a1001heidari@gmail.com
Materials and Methods: This in vitro, experimental study evaluated 108 extracted human third molars, which were randomly divided into six groups $(\mathrm{n}=18)$ of control, Denu-Seal conventional fissure sealant applied on etched enamel with/without saliva contamination, Vertise Flow self-adhesive flowable composite applied on rinsed and dried enamel with/without saliva contamination and Prevent Seal selfadhesive fissure sealant applied on rinsed and dried enamel with/without saliva contamination. Microleakage was assessed using the dye penetration technique and subsequent observation of samples under a stereomicroscope. Data were analyzed using the Kruskal-Wallis and Tukey's test.

Results: Microleakage of the conventional fissure sealant with/without saliva contamination was significantly lower than that of other groups $(\mathrm{P}<0.05)$.

Conclusion: Microleakage of the conventional fissure sealant is less than that of selfadhesive fissure sealant and self-adhesive composite, irrespective of saliva contamination.

Keywords: Pit and Fissure Sealants; Composite Resins; Dental Leakage

$>$ Cite this article as: Hosseinipour Z, Heidari AR, Shahrabi M, Poorzandpoush K. Microleakage of a Self-Adhesive Flowable Composite, a Self-Adhesive Fissure Sealant and a Conventional Fissure Sealant in Permanent Teeth with/without Saliva Contamination. Front Dent. 2019;16(4):239-247. doi:

\section{INTRODUCTION}

Occlusal pits and fissures are highly susceptible to caries particularly in freshly erupted teeth. Sealing of pits and fissures with sealants has been suggested as an effective strategy to decrease the occurrence of caries

This work is published as an open access article distributed under the terms of the Creative Commons Attribution 4.0 License (http://creativecommons.org/licenses/by-nc/4). Non-commercial uses of the work are permitted, provided the original work is properly cited. 
[1]. The preventive effects of fissure sealant therapy directly depend on the flowability of sealants, efficient filling of anatomical defects and their strong and durable bond to tooth structure [2]. Fissure sealants are currently applied for the freshly erupted teeth with deep grooves at high risk of caries [3]. The best time for the application of fissure sealants is immediately after tooth eruption because the newly erupted teeth are less mineralized and are consequently more susceptible to acidic attack $[3,4]$. However, it should be noted that fissure sealants also have a high risk of failure in newly erupted teeth because the distal marginal ridge has just cleared the soft tissue and during the process of sealing of fissures, the occlusal surface is at high risk of saliva contamination $[3,4]$.

Saliva contamination of etched enamel before sealant application is the most common reason for failure of fissure sealants [5]. Evidence shows that application of bonding agent over the etched enamel contaminated with saliva decreases the microleakage, enhances the resin flow into the fissures and increases the short-term clinical success of fissure sealant therapy [6,7].

Several materials and techniques have been proposed to improve the efficacy of fissure sealant therapy such as flowable composites used as fissure sealant material [8]. Selfadhesive flowable composite resins were recently introduced to the market. They contain acidic monomers and do not need separate etching and priming of the tooth surface. The manufacturers claim that these products provide a good marginal seal and prevent over-etching, over-wetting and overdrying [9].

Information about the clinical efficacy of selfadhesive flowable composites is limited, and the available studies in this respect have reported controversial findings. Evidence shows that self-adhesive flowable composites have weak bond strength but optimal marginal seal compared with conventional composites used with a self-adhesive system [9]. Due to fewer clinical steps and easy application, use of these composites as an alternative to fissure sealants seems appealing, especially in pediatric dentistry. Considering the difficulties in behavioral control of pediatric dental patients and difficult isolation, the efficacy of self-adhesive composites for clinical use as an alternative to fissure sealants needs further investigation. This study aimed to assess the microleakage of a self-adhesive flowable composite, a selfadhesive fissure sealant and a conventional fissure sealant in permanent teeth with/without saliva contamination.

\section{MATERIALS AND METHODS}

This in vitro, experimental study evaluated 108 sound third molars, extracted as requested by an oral and maxillofacial surgeon. The study was approved by the Ethics Committee of Tehran University of Medical Sciences (IR.TUMS.DENTISTRY.REC.1396.3480).

Sample size was calculated to be 18 samples in each of the six groups using one-way ANOVA power analysis of PASS II software assuming alpha $=0.05$, beta $=0.2$, standard deviation of 0.12 and effect size of 0.35 .

The teeth were immersed in saline and the solution was refreshed weekly. For disinfection, the teeth were treated with $1 \%$ chloramine T solution for 1 week. The samples were also placed in an ultrasonic bath to clean their surface. The occlusal surface of the teeth was evaluated under a stereomicroscope (EZ4D; Leica, Olympus, Tokyo, Japan) at x10 magnification to exclude teeth with structural defects. Vertise Flow self-adhesive flowable composite (A2 shade; Kerr, Orange, CA, USA), Prevent Seal self-adhesive fissure sealant (ItenaClinica, Paris, France), Denu-Seal conventional fissure sealant (HDI, Seoul, Korea) and 37.5\% phosphoric acid gel (Gel etchant, Kerr, Orange, CA, USA) were used in this study. Chemical composition of these materials is presented in Table 1.

The samples were then randomly divided into six groups $(\mathrm{n}=18)$ as follows:

Group 1 or control group: Etching with 35\% phosphoric acid for 15 seconds, rinsing for 10 seconds, drying the surface with air spray until a frosty appearance was seen, application of Denu-Seal conventional fissure sealant as 
Table 1. Chemical composition of materials used in this study

\begin{tabular}{|l|l|} 
Material & $\begin{array}{l}\text { Chemical composition } \\
\text { Glycerophosphate dimethacrylate, HEMA } \\
\text { pre-polymerized filler } \\
1 \mu \mathrm{m} \text { barium glass filler } \\
\text { nano-sized colloidal silica, nano-sized ytterbium fluoride } \\
\text { Urethane dimethacrylate, Bis-GMA } \\
\text { triethylene glycol dimethacrylate } \\
\text { 2-hydroxyethylmethacrylate, self-etching agent, white pigment, glass filler, } \\
\text { photo-initiator }\end{array}$ \\
\hline Prevent Seal & -Bisphenol A, glycidyl dimethacrylate, fumed silica, photo initiator, colorant \\
\hline Denu Seal & $37.5 \%$ orthophosphoric acid, silica thickener \\
\hline Phosphoric acid gel etchant &
\end{tabular}

recommended by the manufacturer and curing for 20 seconds.

Group 2: Etching as in group 1 followed by drying, saliva contamination of teeth with 0.1 $\mathrm{mL}$ of saliva for 10 seconds, complete drying with air spray, application of Denu-Seal conventional fissure sealant as recommended by the manufacturer and curing for 20 seconds.

Group 3: Rinsing the tooth surface with air and water spray, drying with air spray, application of Prevent Seal fissure sealant as recommended by the manufacturer and curing for 20 seconds.

Group 4: Rinsing the tooth surface with air and water spray, drying with air spray, saliva contamination using $0.1 \mathrm{~mL}$ of saliva for 10 seconds, drying with air spray, application of Prevent Seal fissure sealant as recommended by the manufacturer and curing for 20 seconds. Group 5: Rinsing the tooth surface with air and water spray, drying with air spray, application of Vertise Flow self-adhesive composite as recommended by the manufacturer and curing for 20 seconds.

Group 6: Rinsing the tooth surface with air and water spray, drying with air spray, saliva contamination using $0.1 \mathrm{~mL}$ of saliva for 10 seconds, drying with air spray, application of Vertise Flow self-adhesive composite as recommended by the manufacturer and curing for 20 seconds.

The samples were subjected to 500 thermal cycles between $5-55^{\circ} \mathrm{C}$ with a dwell time of 30 seconds and transfer time of 30 seconds. The apical region of the teeth was then sealed with wax. The entire tooth surface was coated with nail varnish except for $2 \mathrm{~mm}$ around the fissure sealant margin (interface with tooth). Microleakage was assessed using the dye penetration technique. The samples were immersed in silver nitrate solution for 6 hours and were then transferred to a developing solution for 12 hours under florescent light. The teeth were then mounted in self-cure acrylic resin. The teeth were buccolingually sectioned at the mesial, central and distal using a high-speed diamond saw under water coolant (T201A; Mecatome, Presi, France). Longitudinal sections were made. Thus, 4 samples of each tooth crown and 6 surfaces were evaluated. To assess the dye penetration depth for evaluation of microleakage, digital images were obtained of the samples under a stereomicroscope (EZ4D; Leica, Olympus, Tokyo, Japan) at x10 magnification, and the images were then assessed using the respective software. Dye penetration depth was measured by an examiner blinded to the type of material used for sealant therapy in the buccal and lingual surfaces at the enamel/fissure sealant interface and expressed in micrometers $(\mu \mathrm{m})$. The percentage of dye penetration depth in the buccal and lingual was calculated. All measurements were made using MIP software (Fig. 1).

Data were analyzed with SPSS version 22 (SPSS Inc., IL, USA) using the non-parametric KruskalWallis test for multiple comparisons and Tukey's HSD post-hoc test for pairwise comparisons. Level of significance was set at 0.05 . 


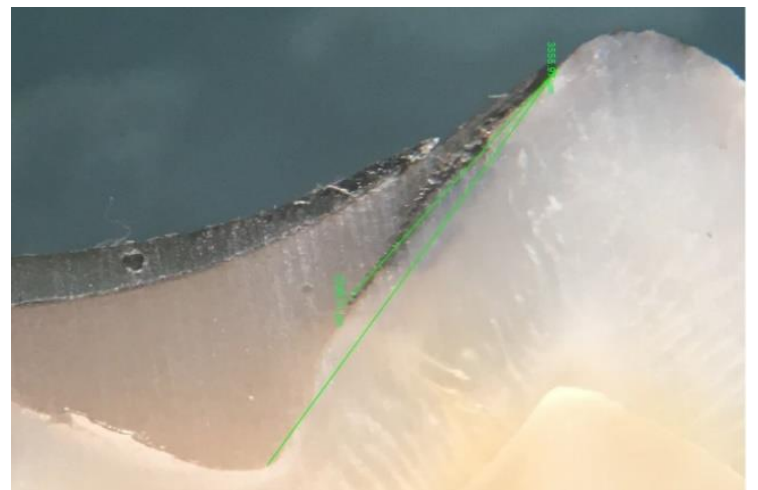

Fig. 1. Tooth-resin interface under a stereomicroscope

\section{RESULTS}

The lowest and the highest dye penetration depth (microleakage) were noted in groups 1 (control) and 4, respectively. The maximum numerical value of microleakage was $100 \%$ observed in all groups and the lowest was $0 \%$ also observed in all groups (Table 2).

Table 2. Mean microleakage according to the percentage of dye penetration in the six groups ( $\mathrm{n}=108$; maximum was 100 and minimum was 0 in all groups)

\begin{tabular}{lc} 
Group & Mean (standard deviation) \\
Control & $9.88(19.34)$ \\
\hline SC+Denu-Seal & $33.86(33.27)$ \\
\hline Prevent Seal & $32.47(40.42)$ \\
SC+Prevent Seal & $51.07(42.10)$ \\
Vertise Flow & $44.93(28.32)$ \\
\hline SC+Vertise Flow & $96.22(26.46)$ \\
\hline
\end{tabular}

Microleakage in group 1 was significantly less than that in other groups $(\mathrm{P}<0.001)$. In all groups, saliva contamination significantly increased the microleakage $(\mathrm{P}<0.05)$.

In non-contaminated groups (groups 1, 3 and 5), microleakage in the Denu-Seal group (group 1) was significantly less than that in groups 3 and $5 \quad(\mathrm{P}<0.001)$. The highest microleakage was noted in Vertise Flow group (group 5).

Among the saliva contaminated groups (groups 2, 4 and 6), microleakage in group 2 (Denu-Seal) was significantly less than that in groups 4 and $6 \quad(\mathrm{P}=0.007$ and $\mathrm{P}<0.001$, respectively). The highest microleakage was noted in Vertise flow group (group 6).

The difference between groups 2 and 3 and also groups 4 and 5 was not significant $(\mathrm{P}=1.00)$. In other words, microleakage of Prevent Seal in isolated conditions was not significantly different from that of Denu-Seal in saliva contaminated samples. Microleakage in use of Vertise Flow in isolated conditions was not significantly different from that of Prevent Seal in saliva contaminated samples (Table 3).

Table 3. Pairwise comparisons of microleakage between the groups using Tukey's test

\begin{tabular}{l|cl}
\hline Group (I) & Group (J) & P-value \\
& 2 & $<0.001$ \\
Control & 3 & 0.01 \\
& 4 & $<0.001$ \\
& 5 & $<0.001$ \\
& 6 & $<0.001$ \\
\hline SC+Denu-Seal & 3 & 1.00 \\
& 4 & 0.017 \\
& 5 & 0.036 \\
\hline Prevent Seal & 6 & $<0.001$ \\
& 4 & $<0.001$ \\
\hline SC+Prevent Seal & 5 & 0.001 \\
\hline Vertise Flow & 6 & $<0.001$ \\
\hline
\end{tabular}

\section{DISCUSSION}

Optimal marginal adaptation is a fundamental factor affecting the efficacy and durability of sealants [10]. Creating an isolated environment is the main parameter in success of fissure sealant treatment. However, it is often challenging to achieve especially in children. One strategy is to use adhesives and self-etch sealants because elimination of rinsing steps decreases the clinical working time and helps in provision of an isolated environment. It can also decrease the risk of contamination and subsequent microleakage [11]. However, a general consensus has not been reached on the efficacy of self-adhesive fissure sealants and flowable composites. Third molar teeth were used in this study since they highly resemble the first and second molars, which commonly require fissure sealant therapy. Microleakage was evaluated 
using the dye penetration technique, which is non-toxic and affordable [12]. Also, thermocycling was performed by applying 500 cycles, which is in accord with the range used in previous studies $[13,14]$.

Self-adhesive restorative materials have a mechanism of action similar to that of self-etch adhesives. Self-etch primers were originally designed for adhesion to dentin since they eliminate the risk of collapse of collagen network due to over-drying after acid etching and rinsing [15]. However, this is not an advantage for bonding to enamel. Higher microleakage of self-adhesive compared with conventional restorative materials may be due to inadequate micromechanical retention between the restorative material and tooth structure as the result of low etching capacity. Separate etching in the conventional method increases the enamel surface energy and creates micro-retentive irregularities on the enamel surface [16]. On the other hand, it has been shown that most self-etch materials do not etch the enamel as deep as the phosphoric acid and this can negatively affect the bonding to enamel [17]. Moreover, separate etching decreases the contact angle of enamel and resin, increases the contact of resin with the enamel surface and enhances the seal [17]. Phosphoric acid etching and subsequent rinsing eliminate prismless enamel; the underlying prismatic structure is consequently exposed and better bonds to fissure sealant. This does not occur in use of self-etch materials [18]. Microscopic studies have demonstrated that resin tags in the enamel are thicker and more uniform following acid etching with phosphoric acid but resin tags formed by the acidic primers in self-etch systems are thin and less uniform, which can result in a weak bond [19].

The acidic materials that remain following the use of self-adhesive systems can prevent adequate polymerization of monomers. Unreacted monomers can decrease the seal and increase microleakage. In the conventional method, elimination of acidic molecules from the bonding area is done by rinsing the etchant [20].
The manufacturer of Vertise Flow claims that the primary bonding mechanism of Vertise Flow is based on chemical reaction between the active phosphate groups in glycerophosphate dimethacrylate molecule and calcium ions in the tooth structure. Acidity of this material depends on the acidic phosphate group in glycerophosphate dimethacrylate molecule.

Another important topic is the need for adequate penetration of etchant into the pits and fissures. Penetration of phosphoric acid into the pits and fissures is much deeper than that of self-etch adhesives [21]. Self-etch adhesives also have optimal wettability due to their hydrophilic nature. However, selfadhesive composites have a higher viscosity and consequently less flowability into pits and fissures; this explains their lower sealing ability when compared with fissure sealants used with total-etch technique. Wadenyaet al, [22] and Parco et al. [23] reported that selfadhesive fissure sealants had significantly higher microleakage than the conventional fissure sealants. Their methodology was similar to ours and their results were in agreement with our findings. Celik et al. [24] compared the microleakage of self-adhesive and conventional composite resins in class $\mathrm{V}$ restorations and showed that self-adhesive composite (Vertise Flow) had significantly higher microleakage at both dentinal and enamel margins compared with the conventional composite. They attributed the higher microleakage of self-adhesive composite to inability to eliminate the smear layer.

Studies comparing the microleakage of selfetch and conventional etch and rinse adhesives have also mainly reported higher microleakage of self-etch adhesives at the enamel margins [25-27]. However, Vichi et al. [28] compared self-adhesive flowable composite and conventional flowable composite bonded with self-etch adhesive and reported less microleakage in self-adhesive flowable composite. Their results were different from ours. But, it should be noted that in fact, they compared self-adhesive 
composite and self-etch adhesive (used for bonding of conventional composite) while this study compared self-adhesive composite with conventional fissure sealant bonded with etch and rinse system. Vichi et al. [28] explained that self-adhesive composites have higher hygroscopic expansion and lower polymerization shrinkage. This would result in a better seal due to higher water sorption by acidic resins $[29,30]$.

Rahimian-Imam et al. [31] and Harsha and Dhruv [32] reported that microleakage of selfadhesive flowable composite was significantly less than that of conventional fissure sealant. They evaluated premolar teeth in their study and assessed microleakage using fuchsine. Such differences in methodology may explain the difference between their results and ours. In the present study, we also evaluated the effect of saliva contamination on microleakage and found that saliva contamination significantly increased the microleakage in all groups. Paschos et al, [33] Fakhri et al, [34] and Campoy et al. [35] indicated that self-etch adhesives are less commonly affected by saliva contamination. This is probably due to the presence of acidic primers, which can penetrate into the surface in presence of bacteria and pellicle. However, our study did not show any superiority for self-adhesive groups compared with total etch in this respect, and Vertise Flow and Prevent Seal in our study were as sensitive to saliva contamination as the Denu-Seal with the total etch system. This finding was similar to that of Parco et al, [23] and may be due to the absence of ethanol and acetone molecules in the structure of self-adhesive materials because it has been reported that ethanol and acetone in single-bottle adhesive systems can degrade glycoproteins and eliminate surface contamination [34].

Another important finding of our study was higher microleakage of Vertise Flow compared with Prevent Seal. Vetise Flow is a flowable composite, which can be used as other flowable composites for sealing of pits and fissures but Prevent Seal has been specifically designed for sealing of pits and fissures. Although the viscosity of flowable composites is lower than that of conventional composites, it is still too high for application as pit and fissure sealant [36]. Evidence shows that sealants have significantly less microleakage than flowable composites [37]. Higher polymerization shrinkage of composite is another reason for this finding. Composite resins with high modulus of elasticity have high polymerization shrinkage. Opdam et al. [38] explained that a critical viscosity threshold exists for wettability of composite resins. Moreover, Irinoda et al. [39] discussed that adequate time must be allowed for efficient penetration of sealants into pits and fissures. In the current study, application of sealants was in accord with the manufacturers' instructions.

Considering all the above, it seems that use of self-adhesive fissure sealant and selfadhesive flowable composite is not suitable for permanent teeth since they are susceptible to microleakage. The current results showed that even in isolated conditions, the microleakage of self-adhesive materials was higher than that of conventional fissure sealant applied on saliva-contaminated tooth surfaces.

Thermal alterations, masticatory forces, chemical acid attacks and the effect of enzymes on the restorative materials that are present in vivo were not simulated in this in vitro study. We used thermocycling to simulate the clinical setting as much as possible. However, evidence shows that even after thermocycling, microleakage of restorative materials in vitro is less than that in vivo [40]. But, it should be noted that inability to perfectly simulate oral conditions in vitro does not affect the results of comparison of several restorative materials, because they are all compared under similar conditions. Future studies are required to evaluate the gap at the enamel-restoration interface using scanning electron microscopy because Hannig et al. [25] discussed that dye penetration at the tooth-restoration interface does not necessarily indicate presence of gap; it can also be due to the type of dye and absorption of dye by the self-adhesive molecules. 


\section{CONCLUSION}

Within the limitations of this in vitro study, the results showed that Vertise flow and Prevent Seal cannot provide adequate seal since their microleakage in this study was significantly higher than that of conventional fissure sealant. Saliva contamination significantly increased the microleakage in all groups.

\section{ACKNOWLEDGMENTS}

This study was funded and supported by Tehran University of Medical Sciences (TUMS), grant no: 9411276002 .

\section{CONFLICT OF INTEREST STATEMENT}

None declared.

\section{REFERENCES}

1. Papageorgiou SN, Dimitraki D, Kotsanos N, Bekes $\mathrm{K}$, van Waes $\mathrm{H}$. Performance of pit and fissure sealants according to tooth characteristics: A systematic review and meta-analysis. J Dent. 2017 Nov;66:8-17.

2. Ahovuo-Saloranta A, Forss H, Walsh T, Nordblad A, Mäkelä M, Worthington HV. Pit and fissure sealants for preventing dental decay in permanent teeth. Cochrane Database Syst Rev. 2017 Jul 31;7:CD001830.

3. Simonsen RJ. Pit and fissure sealant: review of the literature. Pediatr Dent. 2002 Sep-Oct;24(5):393-414.

4. Feigal RJ. The use of pit and fissure sealants. Pediatr Dent. 2002 SepOct;24(5):415-22.

5. Barroso JM, Torres CP, Lessa FC, Pécora JD, Palma-Dibb RG, Borsatto MC. Shear bond strength of pit-and-fissure sealants to saliva-contaminated and noncontaminated enamel. J Dent Child (Chic). 2005 SepDec;72(3):95-9.

6. Torres CP, Balbo P, Gomes-Silva JM, Ramos RP, Palma-Dibb RG, Borsatto MC. Effect of individual or simultaneous curing on sealant bond strength. J Dent Child (Chic). 2005 Jan-Apr;72(1):31-5.

7. Borsatto MC, Corona SAM, Alves A, Chimello D, Catirse A, Palma-Dibb R. Influence of salivary contamination on marginal microleakage of pit and fissure sealants. Am J Dent. 2004 Oct;17(5):365-7.

8. Donly KJ. Sealants: where we have been; where we are going. Gen Dent. 2002 SepOct;50(5):438-40.

9. Autio-Gold JT. Clinical evaluation of a medium-filled flowable restorative material as a pit and fissure sealant. Oper Dent. 2002 JulAug;27(4):325-9.

10. Ganesh M, Shobha T. Comparative evaluation of the marginal sealing ability of Fuji VII and Concise as pit and fissure sealants. J Contemp Dent Pract. 2007 May 1;8(4):10-8.

11. Gomes-Silva JM, Torres CP, Contente MM, Oliveira MA, Palma-Dibb RG, Borsatto MC. Bond strength of a pit-and-fissure sealant associated to etch-and-rinse and self-etching adhesive systems to saliva-contaminated enamel: individual vs. simultaneous light curing. Braz Dent J. 2008;19(4):341-7.

12. Matharu S, Spratt DA, Pratten J, Ng YL, Mordan $\mathrm{N}$, Wilson $\mathrm{M}$, et al. A new in vitro model for the study of microbial microleakage around dental restorations: a preliminary qualitative evaluation. Int Endod J. 2001 Oct;34(7):547-53.

13. Pérez-Lajarín L, Cortés-Lillo 0, GarcíaBallesta C, Cózar-Hidalgo A. Marginal microleakage of two fissure sealants: a comparative study. J Dent Child (Chic). 2003 Jan-Apr;70(1):24-8.

14. Atash $\mathrm{R}$, Bottenberg $\mathrm{P}$, Petein $\mathrm{M}$, Abbeele AV. In vitro evaluation of the marginal seal of four restoration materials on deciduous molars. Bull Group Int Rech Sci Stomatol Odontol. 2008;45(1):34-41.

15. Kugel G, Ferrari M. The science of bonding: from first to sixth generation. J Am Dent Assoc. 2000 Jun;131 Suppl:20S-25S.

16. Cehreli SB, Eminkahyagil N. Effect of active pretreatment of self-etching primers on the ultramorphology of intact primary and permanent tooth enamel. J Dent Child (Chic). 2006 May-Aug;73(2):86-90.

17. Shinohara MS, de Oliveira MT, Di Hipólito V, Giannini M, de Goes MF. SEM analysis of the acid-etched enamel patterns promoted by acidic monomers and phosphoric acids. J Appl Oral Sci. 2006 
Dec;14(6):427-35.

18. Kanemura N, Sano H, Tagami J. Tensile bond strength to and SEM evaluation of ground and intact enamel surfaces. J Dent. 1999 Sep;27(7):523-30.

19. Van Landuyt KL, Kanumilli P, De Munck J, Peumans M, Lambrechts P, Van Meerbeek B. Bond strength of a mild self-etch adhesive with and without prior acid-etching. J Dent. 2006 Jan;34(1):77-85.

20. Woody TL, Davis RD. The effect of eugenol-containing and eugenol-free temporary cements on microleakage in resin bonded restorations. Oper Dent. 1992 SepOct;17(5):175-80.

21. dos Santos KT, Sundfeld RH, Garbin CA, de Alexandre RS, Sundefeld ML, Ceolim BN. Length of resin tags in pit-and-fissure sealants: all-in-one self-etching adhesive vs phosphoric acid etching. Compend Contin Educ Dent. 2008 Apr;29(3):186-92.

22. Wadenya RO, Yego C, Blatz MB, Mante F. Bond strength and microleakage of a new self-etch sealant. Quintessence Int. 2009 JulAug;40(7):559-63.

23. Parco TM, Tantbirojn D, Versluis A, Beiraghi S. Microleakage of self-etching sealant on noncontaminated and salivacontaminated enamel. Pediatr Dent. 2011 Nov-Dec;33(7):479-83.

24. Celik EU, Kucukyilmaz E, Savas S. Effect of different surface pre-treatment methods on the microleakage of two different self-adhesive composites in Class $\mathrm{V}$ cavities. Eur J Paediatr Dent. 2015 Mar;16(1):33-8.

25. Hannig M, Gräfe A, Atalay S, Bott B. Microleakage and SEM evaluation of fissure sealants placed by use of self-etching priming agents. J Dent. 2004 Jan;32(1):75-81.

26. Bassir L, Khanehmasjedi M, Nasr E, Kaviani A. An in vitro comparison of microleakage of two self-etched adhesive and the one-bottle adhesive used in pit and fissure sealant with or without saliva contamination. Indian J Dent Res. 2012 Nov-Dec;23(6):80610.

27. Shadman N, Farzin Ebrahimi Sh, Molaie N. Microleakage of total-etch and selfetch adhesives in class $\mathrm{V}$ composite cavities. J Dent Med. 2010 Dec;23(4):227-34.
28. Vichi A, Margvelashvili M, Goracci C, Papacchini F, Ferrari M. Bonding and sealing ability of a new self-adhering flowable composite resin in class I restorations. Clin Oral Investig. 2013 Jul;17(6):1497-506.

29. Ito $\mathrm{S}$, Hoshino $\mathrm{T}$, Iijima $\mathrm{M}$, Tsukamoto N, Pashley DH, Saito T. Water sorption/solubility of self-etching dentin bonding agents. Dent Mater. 2010 Jul;26(7):617-26.

30. Bortolotto T, Mileo A, Krejci I. Strength of the bond as a predictor of marginal performance: an in vitro evaluation of contemporary adhesives. Dent Mater. 2010 Mar;26(3):242-8.

31. Rahimian-Imam S, Ramazani N, Fayazi MR. Marginal Microleakage of Conventional Fissure Sealants and Self-Adhering Flowable Composite as Fissure Sealant in Permanent Teeth. J Dent (Tehran). 2015 Jun;12(6):430-5. 32. Harsha PP, Dhruv KV. Comparative Evaluation of Marginal Microleakage of Conventional Fissure Sealants and Selfadhering Flowable Composites as Fissure Sealant in Permanent Teeth-An In Vitro Study. Int J Sci Study. 2017 May 1;5(2):36-40.

33. Paschos E, Westphal JO, Ilie N, Huth KC, Hickel R, Rudzki-Janson I. Artificial saliva contamination effects on bond strength of selfetching primers. Angle Orthod. 2008 Jul;78(4):716-21.

34. Fakhri M, Seraj B, Shahrabi M, Motahhary P, Hooshmand T. Effect of salivary contamination on microleakage of resin composites placed with a self-etch adhesive in primary teeth: an in vitro study. Pediatr Dent. 2009 Jul-Aug;31(4):334-9.

35. Campoy MD, Plasencia E, Vicente A, Bravo LA, Cibrián R. Effect of saliva contamination on bracket failure with a selfetching primer: a prospective controlled clinical trial. Am J Orthod Dentofacial Orthop. 2010 May;137(5):679-83.

36. Kwon HB, Park KT. SEM and microleakage evaluation of 3 flowable composites as sealants without using bonding agents. Pediatr Dent. 2006 Jan-Feb;28(1):48-53. 37. Chaitra TR, Subba Reddy VV, Devarasa GM, Ravishankar TL. Flowable resin used as a sealant in molars using conventional, 
enameloplasty and fissurotomy techniques: an in vitro study. J Indian Soc Pedod Prev Dent. 2010 Jul-Sep;28(3):145-50.

38. Opdam NJ, Roeters JJ, Joosten M, Veeke OV. Porosities and voids in Class I restorations placed by six operators using a packable or syringable composite. Dent Mater. 2002 Jan;18(1):58-63.

39. Irinoda $\mathrm{Y}$, Matsumura $\mathrm{Y}$, Kito $\mathrm{H}$,
Nakano T, Toyama T, Nakagaki H, et al. Effect of sealant viscosity on the penetration of resin into etched human enamel. Oper Dent. 2000 Jul-Aug;25(4):274-82.

40. Pardi V, Sinhoreti MA, Pereira AC, Ambrosano GM, Meneghim Mde C. In vitro evaluation of microleakage of different materials used as pit-and-fissure sealants. Braz Dent J. 2006;17(1):49-52. 